\title{
Thermal protection of rocket nozzle by using film cooling technology - effect of lateral curvature
}

\author{
Ahmed Guelailia ${ }^{1 *}$, Azzeddine Khorsi ${ }^{2}$, Abdelmadjid Boudjemai ${ }^{1}$, Jin Wang ${ }^{3,4}$ \\ ${ }^{1}$ Centre of Satellite Development (CDS), Space Mechanical Research Department, BP 4065 Ibn Rochd USTO, Oran 31001, \\ Algeria \\ ${ }^{2}$ University of Sciences and Technology of Oran, Laboratory of Applied Mechanics, BP 1505, El M'Nouar, Oran 31001, \\ Algeria \\ ${ }^{3}$ School of Energy and Environmental Engineering, Hebei University of Technology, Tianjin 300130, China \\ ${ }^{4}$ Department of Energy Sciences, Division of Heat Transfer, Lund University, Lund 22100, Sweden
}

Corresponding Author Email: guelailia@yahoo.fr

https://doi.org/10.18280/ijht.360338

Received: 3 December 2017

Accepted: 28 August 2018

\author{
Keywords: \\ computational fluid dynamics, heat and \\ mass transfer, thermal protection, rocket \\ nozzle, film cooling, propulsion
}

\begin{abstract}
The present paper aims to analyze the applicability of film cooling method to a rocket as a thermal protection. Lateral curvature effect on film cooling performance through a single row of cylindrical holes with different spanwise angles is investigated. Four different lateral curvature cases $(\mathrm{C}=\infty, 100,60,20)$ with four inclination angles of cooling injection holes $\left(\beta=35^{\circ}, 45^{\circ}, 55^{\circ}, 65^{\circ}\right)$ are considered. The ANSYS CFX has been used for this computational simulation. The turbulence is approximated by a shear stress transport model (SST). Detailed film effectiveness distributions are presented for several blowing ratios $(0.5,1$ and 1.5$)$. The numerical results are compared with experimental data.
\end{abstract}

\section{INTRODUCTION}

Thermal protection of rocket engines of spacetransportation systems is one of the most challenging issues. The heat loads and temperatures in combustion chambers and rocket nozzles are significantly above the material failure limit of recent available materials. Efficient cooling methods are necessary in order to reduce thermal loads and insure reliability of rocket engines. Cooling techniques such as regenerative cooling, radiation cooling, film cooling, transpiration cooling and ablation have led to improvements in nozzles thermal protection [1]. Film cooling technology is one of the favorable cooling methods. In this technique, a secondary fluid is injected through holes on the surface to be cooled. The injected coolant from holes forms a thin thermal insulation layer on the surface to protect the wall from being overheated by the hot flow.

For several decades, considerable attention has been paid to film cooling applied to gas turbine blades. A film cooling process depends on many parameters. Primary physical properties, that influence film cooling, are: a coolant-to-hot mainstream velocity ratio, blowing ratio [2], momentum ratio, pressure ratio, temperature ratio, density ratio and turbulence intensity [3-4]. Also, the geometrical characteristics have a bearing on film cooling. Therefore, geometry of the film cooling holes, their distribution and location have been widely studied.

Among the earlier studies, A. Guelailia et al. [5] investigated the effect of mass flow rate on film cooling effectiveness and heat transfer over a gas turbine rotor blade. To improve film cooling effectiveness, the cylindrical holes, located on the leading edge region, are replaced with the converging slot holes (console). They indicated that converging slot holes provide better film cooling protection than simple cylindrical holes. A. Khorsi et al. [6] studied numerically the influence of a downstream crescent-shaped block on the flow field and film cooling effectiveness over a flat plate. It was found that the use of a downstream short crescent-shaped block as a coolant flow deflector body reveals a significant film cooling effectiveness, as compared to the simple case without the block. Ke Tian et al. [7] investigated the effects of hole blockage configurations on film cooling characteristics. The effect of upstream bulge configurations on film cooling effectiveness was investigated by Q. Li and al [8]. The film-cooling performance of the console rows on a nozzle vane when all the hole rows were open was measured in the work of J.E. Sargison et al. [9]. The authors of the works [10-12] studied the effects of surface roughness on adiabatic effectiveness using a flat plate and saw little degradation in adiabatic effectiveness. The works [13-16] presented the detailed experimental data of the film cooling effectiveness and heat transfer coefficient for single and rows of holes in a flat plate.

To our knowledge, investigations on film cooling were mainly performed on gas turbines and a few investigations have been conducted on film cooled rocket engines. However, most of the previous studies do not take into account the effects of some parameter specific to rockets on film cooling effectiveness such as high density and blowing ratios, specific heat differences between coolant and main flow fluid, lateral curvature. Lucas et al. [17] investigated film cooling in a rocket combustion chamber. A. L. Kumarl et al. [18] studied the effect of coolant injector configuration on overall film cooling performance in a divergent section of a rocket nozzle. An investigation was made by J. F. McCall et al. [19] in order to analyze the influence of radial curvature and compound angle on film cooling in a LOX / kerosene converging nozzle section. 
One of the main differences between gas turbine blades and rocket nozzles is the wall curvature. Turbine blade walls are curved in the stream-wise direction, while rocket nozzles walls can be curved in both streamwise and spanswise directions. Most film cooling studies have only focused on flat plates or surfaces with stream-wise curvature. The purpose of this study is to investigate the effect of lateral curvature on film cooling effectiveness through a single row of cylindrical holes with different spanwise injection angles at various blowing ratios using a shear stress transport model (SST). The predicted results are compared with the experimental results of $\mathrm{H}$. Nasir and al [20].

\section{NUMERICAL METHOD}

The simulations were performed using the Ansys CFX software. In the solver package, the solution of the Reynoldsaveraged Navier-Stokes equations is obtained by using the finite volume method to discretize the continuity, momentum, and energy equations. The calculation is continued until the convergence criterion $\left(10^{-5}\right)$ is met. In this study, the turbulence is modeled by a shear stress transport model (SST) of Menter [21], which incorporates the advantages of both the $\mathrm{k}-\varepsilon$ and $\mathrm{k}-\omega$ models.

\section{GEOMETRY}

The baseline configuration used in the present work is a flat plate which has been studied experimentally in the work of $\mathrm{H}$. Nasir et al. [20]. The pitch-to-diameter ratio p/d in the spanwise direction is 3 with a nominal hole diameter $\mathrm{d}=12.7$ $\mathrm{mm}$. The $\mathrm{x}$ coordinate is measured from the downstream edge of the injection hole and is used in a dimensionless form as $\mathrm{x} / \mathrm{d}$. Four different lateral curvature cases $(\mathrm{C}=\infty, 100,60,20)$ with four inclination angles of cooling injection holes in the spanwise direction $\left(\beta=35^{\circ}, 45^{\circ}, 55^{\circ}, 65^{\circ}\right)$ are investigated. It should be noted that when $\mathrm{C} \rightarrow \infty$, the flat plate is approached. The geometry of the flat plate which corresponds to the baseline configuration is illustrated in Figure 1. The lateral curved configuration with $\mathrm{C}=20$ is presented in Figure 2. The inlet plane is positioned at $\mathrm{x} / \mathrm{d}=8$ upstream from the center of the upwind hole, while the exit plane is at $\mathrm{x} / \mathrm{d}=30$ downstream. The computational domain extends to a height of $\mathrm{y} / \mathrm{d}=5$ and the discharge hole is $6 \mathrm{~d}$ long.

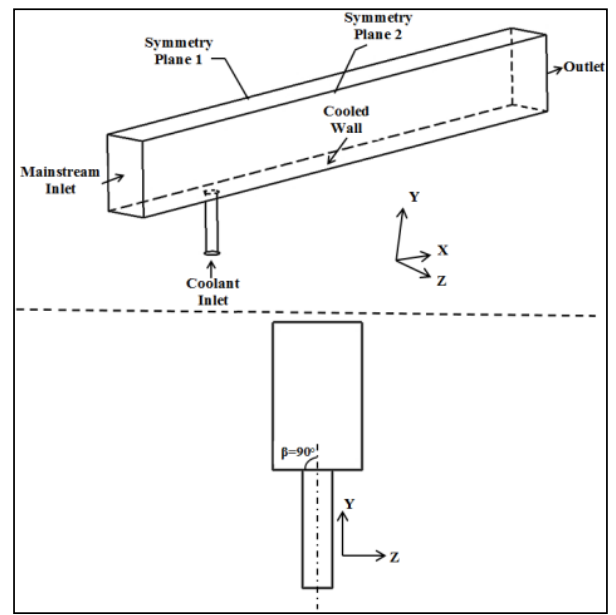

Figure 1. Geometry of the baseline configuration

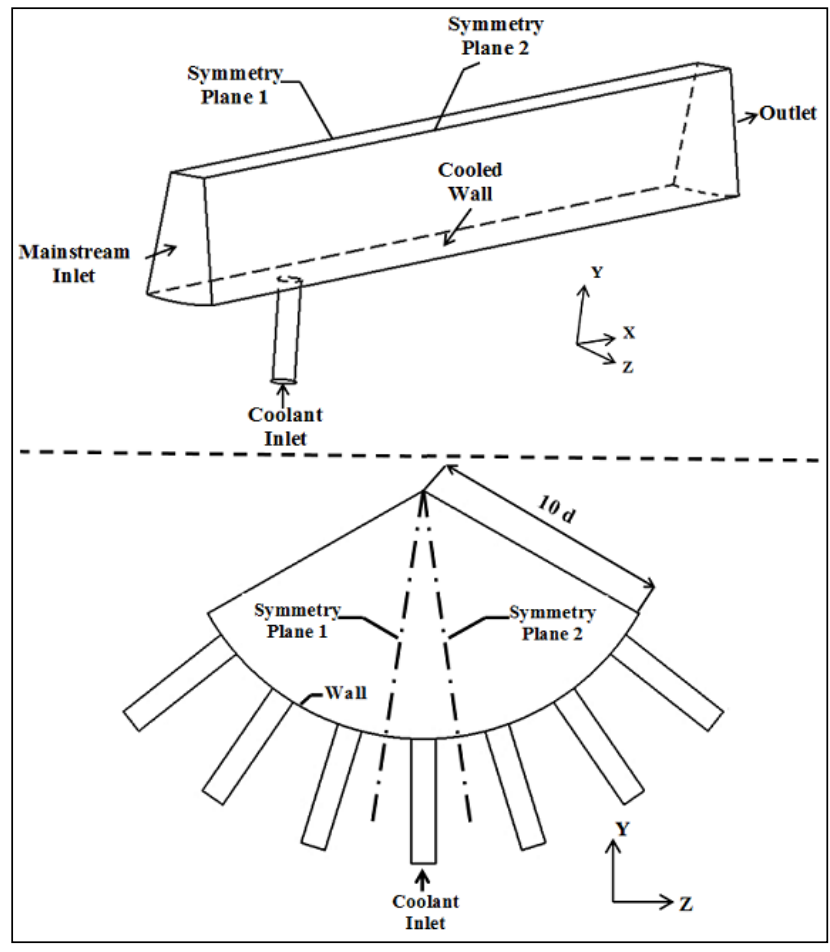

Figure 2. Geometry of the lateral curved configuration

\section{MESH GENERATION}

The computational grid has been obtained using the commercial grid generator ICEM. The numerical domain is discretized using a structured multi-block grid. The final grid adopted for calculations was obtained after a series of tests. Three structured grids were generated and referred to as coarse, medium, and fine, comprising 759,281, 1,103,292, and $1,573,068$ hexahedral elements, respectively. The grid was considerably refined in the near-wall region and in the injection hole vicinity. The values of $y^{+}$at near-wall nodes were kept smaller than two $\left(\mathrm{y}^{+}<2\right)$. A preliminary grid dependence study showed that the medium structured grid with 1,103,292 elements was the best compromise between the precision and available computational facilities. Figure 3 shows the multi-block grid used for this simulation and the zoomed region in the vicinity of the injection hole.

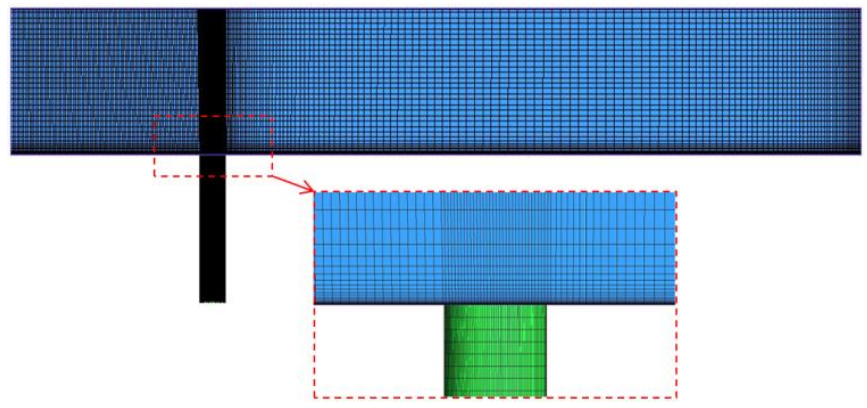

Figure 3. Computational grid

\section{BOUNDARY CONDITIONS}

Details on the boundary conditions and the physical parameters are given in the Table 1. Boundary conditions are prescribed at all boundaries of the computational domain. The 
periodic conditions were used for two lateral planes. The plate and the hole walls were assigned to be adiabatic walls with noslip conditions. The velocity profile at the computational domain inlet was determined by the formula $U_{\text {in }}=U_{\infty}\left(y / \delta^{*}\right)^{1 / 7}$, where $\delta^{*}$ is the boundary layer thickness estimated as one hole diameter. A certain value of pressure was prescribed at the outlet boundary.

Table 1. Simulation parameter conditions

\begin{tabular}{|c|c|c|c|}
\hline \multicolumn{2}{|c|}{ Boundary conditions } & \multicolumn{2}{c|}{ Physical parameters } \\
\hline $\mathbf{U}_{\infty}[\mathbf{m} / \mathbf{s}]$ & 12 & $\mathbf{d}[\mathbf{m m}]$ & 12.7 \\
$\mathbf{T}_{\infty}[\mathbf{K}]$ & 331.15 & $\mathbf{C}=\boldsymbol{d}_{\infty} / \boldsymbol{d}$ & $\infty, 100,60,20$ \\
$\mathbf{T}_{\mathbf{c}}[\mathbf{K}]$ & 298.15 & $\mathbf{p} / \mathbf{d}$ & 3 \\
$\mathbf{D R}$ & 1 & $\mathbf{y} / \mathbf{d}$ & 5 \\
$\mathbf{T u}$ & $10 \%$ & $\boldsymbol{\beta}\left[{ }^{\circ}\right]$ & $35,45,55,65$ \\
$\boldsymbol{M}=\boldsymbol{\rho}_{\boldsymbol{c}} \boldsymbol{U}_{\boldsymbol{c}} /\left(\boldsymbol{\rho}_{\infty} \boldsymbol{U}_{\infty}\right)$ & $0.5,1,1.5$ & & \\
\hline
\end{tabular}

\section{RESULTS AND DISCUSSION}

In the present work, the results of adiabatic and laterally averaged film cooling effectiveness which are defined respectively by equations (1) and (2) were investigated at different blowing ratios depending on operating conditions as shown in the Table 1.

$\eta=\frac{T_{\infty}-T}{T_{\infty}-T_{c}}$

$\bar{\eta}=\frac{1}{L} \int_{L} \eta d y$

where $\mathrm{L}$ represents the spanwise dimension.

In order to validate the calculation method, the laterally averaged adiabatic film effectiveness calculated by equation (2) for $\beta=55^{\circ}$ and $M=1$ is compared with the experimental work of H. Nasir et al. [20] as shown in Figure 4. The results of the present study agree well with the experimental data of [20].

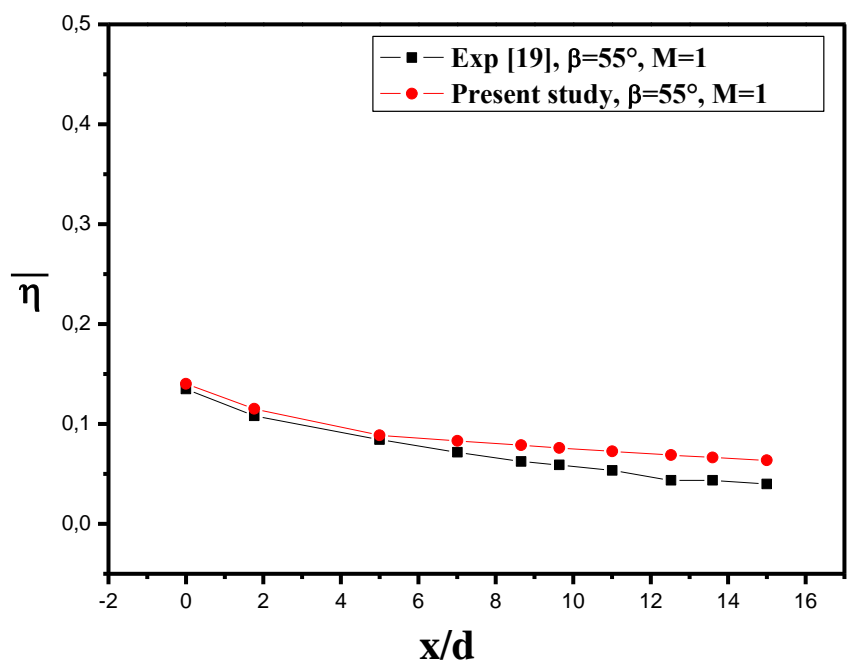

Figure 4. Laterally averaged adiabatic film cooling effectiveness

Figure 5 presents the effect of lateral curvature on area- averaged effectiveness at various blowing ratios $\mathrm{M}=0.5,1,1.5$ with inclined injection angle $\beta=35^{\circ}$. For the curved wall cases $(\mathrm{C}=100,60,20)$, the highest area-averaged effectiveness is obtained at higher blowing ratio $(\mathrm{M}=1.5)$, contrary to flat wall case $(\mathrm{C}=\infty)$ which shows the maximum area average effectiveness value at $\mathrm{M}=1$. It can be seen also that, for $\mathrm{M}=0.5$ and $\mathrm{M}=1$, the area average effectiveness increases with decreasing wall curvature. Maximum effectiveness value was obtained for the flat plate case $(\mathrm{C}=\infty)$. However, for high blowing ratio $\mathrm{M}=1.5$, the area average effectiveness is proportional to the wall curvature until an optimum value of $\mathrm{C}=60$, after that the tendency is inverted and lower values were found for wall lateral curvature $\mathrm{C}=20$.

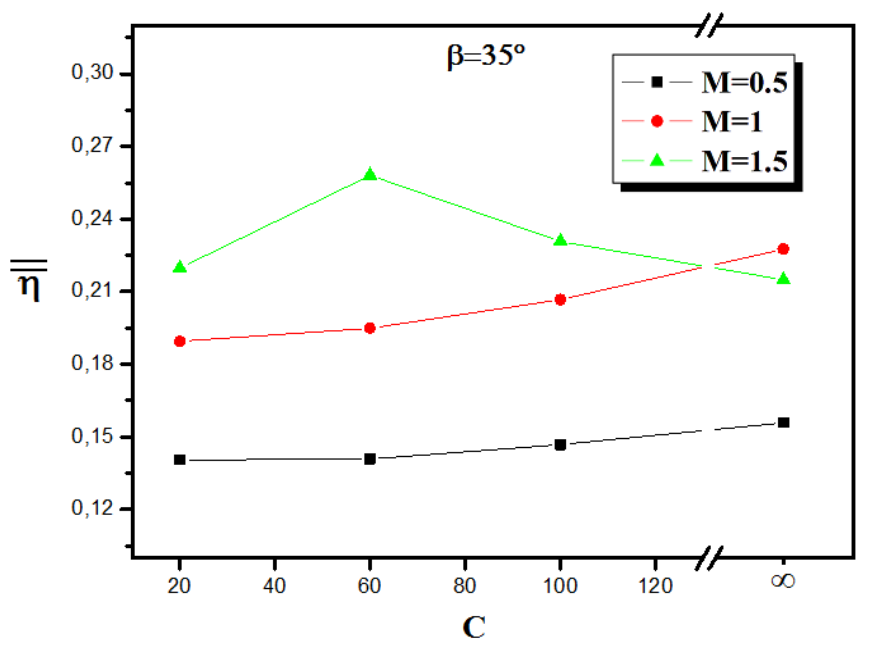

Figure 5. Lateral curvature effect on area-averaged effectiveness at various blowing ratios

Laterally averaged adiabatic film cooling effectiveness at different lateral curvatures $C=20,60,100, \infty$ for $M=1$ and $\beta=35^{\circ}$ is shown in Figure 6. Lateral average effectiveness for flat wall case $(C=\infty)$ is significantly higher than that in curved wall cases $(C=100,60,20)$, this is due to the coolant spread in the lateral direction when the wall form is flat. For the most curved wall case $(C=20)$, lower lateral average effectiveness is observed at $\mathrm{x} / \mathrm{d}<13$. However, at $\mathrm{x} / \mathrm{d}>13$, the coolant become more efficient compared to other curved wall cases $C=100$ and $\mathrm{C}=60$.

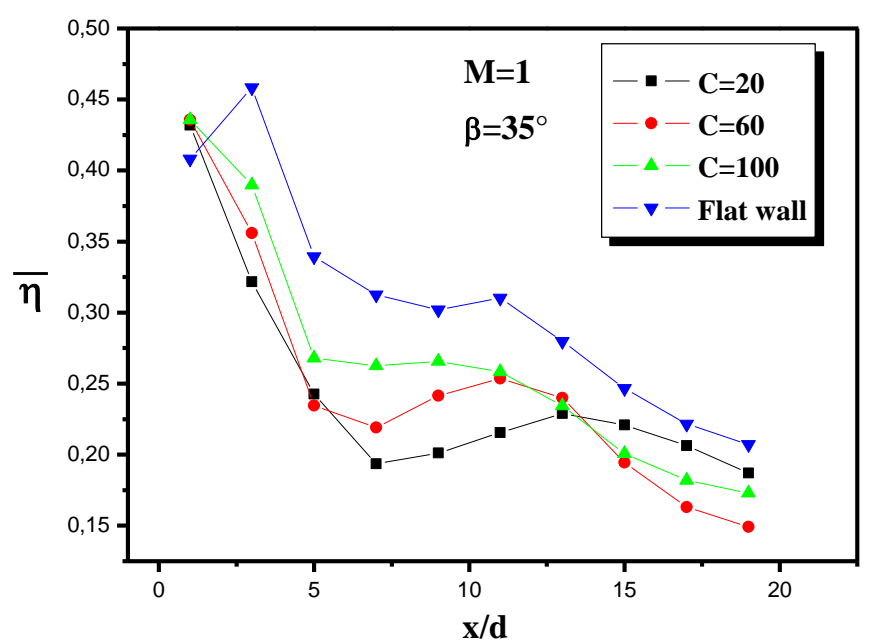

Figure 6. Laterally averaged adiabatic film cooling effectiveness at various lateral curvatures 
Based on the present simulation, figure 7 shows the lateral curvature effect on area-averaged effectiveness at various injection angles $\beta=35^{\circ}, 45^{\circ}, 55^{\circ}, 65^{\circ}$ for $M=1$. Seemingly, for all cases, the coolant injection from smaller angle $\left(\beta=35^{\circ}\right)$ promises a greater area average effectiveness than the injection from other angles $\beta=45^{\circ}, 55^{\circ}, 65^{\circ}$. Thus, film cooling effectiveness is more affected by lateral curvature in the case where $\beta=35^{\circ}$. It's also seen that as lateral curvature decrease, the influence of injection angle becomes bigger, especially for the plat wall case $(\mathrm{C}=\infty)$.

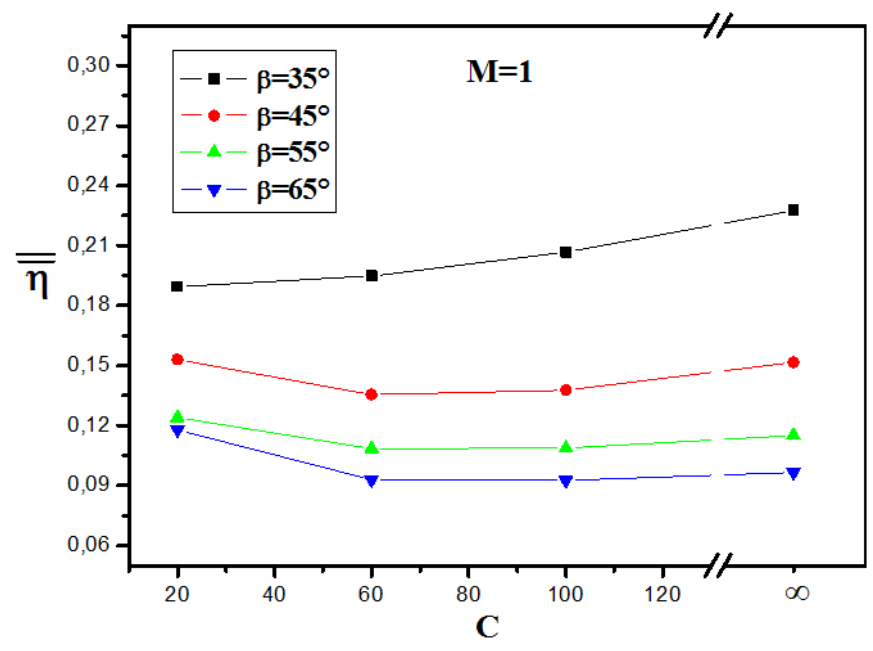

Figure 7. Lateral curvature effect on area-averaged effectiveness at various injection angles

Laterally averaged adiabatic film cooling effectiveness for the more lateral curved case $(\mathrm{C}=20)$ at various injection angles $\beta=35^{\circ}, 45^{\circ}, 55^{\circ}, 65^{\circ}$ and $\mathrm{M}=1$ is illustrated in Figure 8. It's clear that the lateral averaged film cooling effectiveness is significantly high when the injection hole is well inclined $(\beta=$ $\left.35^{\circ}\right)$ in comparison with other inclination angles $\left(\beta=45^{\circ}, 55^{\circ}\right.$, $\left.65^{\circ}\right)$. No significant variation of lateral average effectiveness can be cited for $\beta=55^{\circ}$ and $\beta=65^{\circ}$.

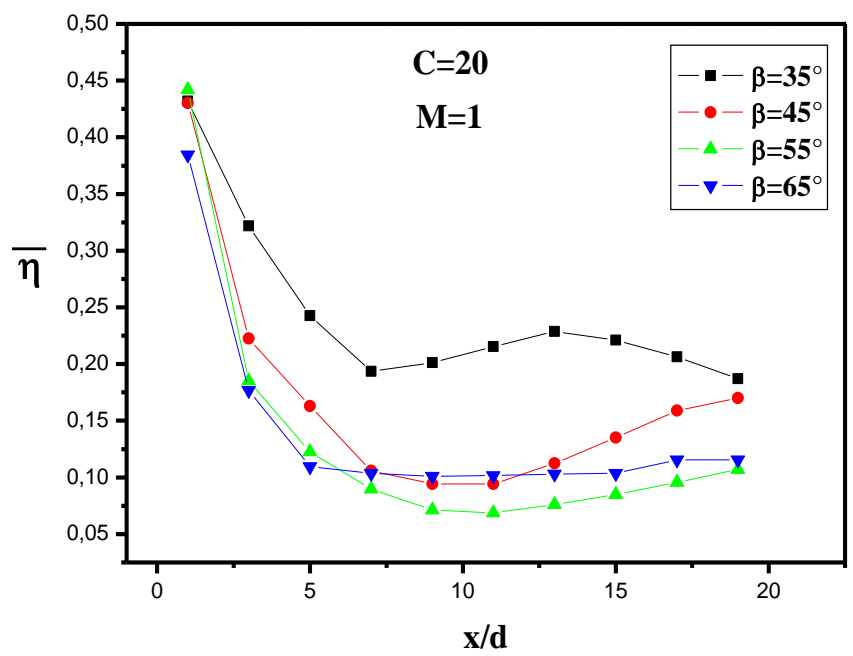

Figure 8. Laterally averaged adiabatic film cooling effectiveness at various injection angles

The contours of film effectiveness distributions for the most curved case $\mathrm{C}=20$ at different blowing ratios $(\mathrm{M}=0.5,1,1.5)$ for $\beta=35^{\circ}$ are shown in Figure 9. It can be seen that increasing blowing ratio can enhance film cooling effectiveness. Thus, a better film coverage is obtained at high blowing ratio $\mathrm{M}=1.5$ compared to lower ones. It is also clear that the whole wall is cooled when $\mathrm{M}=1.5$. However, for $\mathrm{M}=0.5$ and $\mathrm{M}=1$, some wall parts need to be covered by the cooling film.

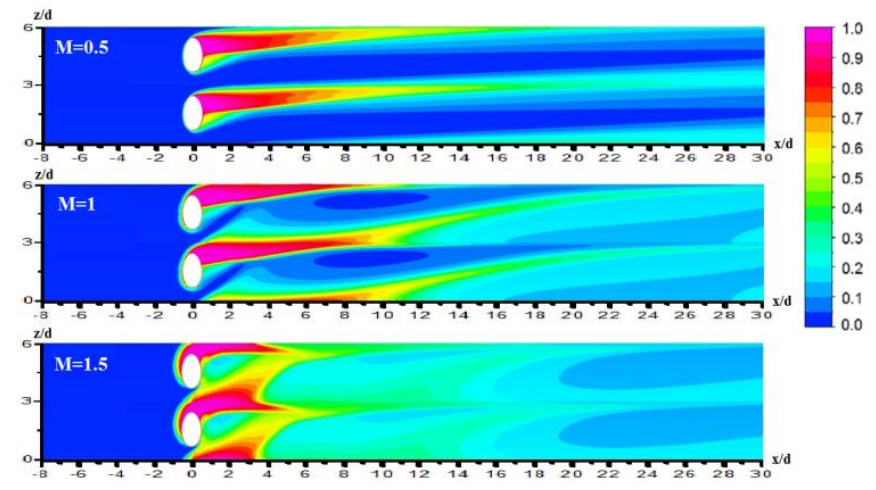

Figure 9. Film cooling effectiveness distributions at different blowing ratios for $C=20$ and $\beta=35^{\circ}$

\section{CONCLUSIONS}

In this paper, the applicability of film cooling method to a nozzle as a thermal protection was numerically analyzed by investigating the lateral curvature effect on film cooling performance through a single row of cylindrical holes. Four different lateral curvature cases $(\mathrm{C}=\infty, 100,60,20)$ was considered. The shear stress transport (SST) turbulence model has been employed to simulate the three dimensional flow field and the film cooling effectiveness by ANSYS CFX code. An acceptable agreement with previous experimental measurements $(\mathrm{C}=\infty)$ has been obtained. Detailed film effectiveness distributions are presented for several blowing ratios $(0.5,1$ and 1.5) and different spanwise injection angles $\left(\beta=35^{\circ}, 45^{\circ}, 55^{\circ}, 65^{\circ}\right)$. Summing up the results, it can be concluded that the film cooling effectiveness is more affected by lateral curvature in the case where the injection angle is small $\left(\beta=35^{\circ}\right)$. In all cases, the coolant injection from smaller angle $\left(\beta=35^{\circ}\right)$ promises a greater laterally-average and areaaverage effectiveness compared to other angles $\beta=45^{\circ}, 55^{\circ}$, $65^{\circ}$. It was also found that the optimum area-averaged film cooling effectiveness is obtained at higher blowing ratio $(M=1.5)$ for the curved wall cases $(C=100,60,20)$. Contrariwise, when the cooled wall is flat $(C=\infty)$, the maximum area-average effectiveness is observed at $\mathrm{M}=1$. In addition, for $\mathrm{M}=0.5$ and $\mathrm{M}=1$, the area average effectiveness increases when the wall curvature decreased. However, for $\mathrm{M}=1.5$, the area-average effectiveness increases with increasing the wall curvature until an optimum value of $\mathrm{C}=60$, after that the tendency is inverted and lower values were found for wall lateral curvature $\mathrm{C}=20$. For the most curved wall case $(C=20)$, lower lateral average effectiveness is observed at $\mathrm{x} / \mathrm{d}<13$. However, at $\mathrm{x} / \mathrm{d}>13$, the coolant become more efficient compared to other curved wall cases $\mathrm{C}=100$ and $\mathrm{C}=60$.

\section{ACKNOWLEDGMENT}

The corresponding author, GUELAILIA Ahmed, dedicates this paper to the memory of Professor ABIDAT Miloud. 


\section{REFERENCES}

[1] Coulbert CD. (1964). Selecting cooling techniques for liquid rockets for spacecraft. Journal of Spacecraft and Rockets 1(2): 129-139. http://doi.org/10.2514/3.27612

[2] Drost U, Bölcs A. (1999). Investigation of detailed film cooling effectiveness and heat transfer distributions on a gas turbine airfoil. ASME J. Turbomachinery 121: 233242. http://doi.org/10.1115/1.2841306

[3] Ammari HD, Hay N, Lampard D. (1990). The effect of density ratio on the heat transfer coefficient from a film cooled flat plate. ASME J. Turbomachinery 112: 444450. http://doi.org/10.1115/1.2927679

[4] Sinha AK, Bogard DG, Crawford ME. (1991). Filmcooling effectiveness downstream of a single row of holes with variable density ratio. ASME J. Turbomachinery 113: 442-449. http://doi.org/10.1115/1.2927894

[5] Guelailia A, Khorsi A, Hamidou MK. (2016). Computation of leading edge film cooling from a console geometry (converging slot hole). Thermophysics and Aeromechanics 23(1). http://doi.org/10.1134/S0869864316010042

[6] Khorsi A, Guelaili A, Hamidou MK. (2016). Improvement of film cooling effectiveness with a small downstream block body. Journal of Applied Mechanics and Technical Physics 57(4). http://doi.org/10.1134/S0021894416040106

[7] Tian K, Wang J, Zhanxiu C, Guelailia A. (2017). Effect of hole blockage configurations on film cooling in gas turbine components. Chemical Engineering Transactions 61. http://doi.org/10.3303/CET1761036

[8] Li Q, Wang J, Min C, Tian K, Tian L, Sundén B. (2017). Effect of an upstream unconnected bulge on film cooling. Chemical Engineering Transactions 61. http://doi.org/10.3303/CET1761035

[9] Sargison JE, Guo SM, Oldfield MLG, Lock GD, Rawlinson AY, Xu DCh. (2002). A converging slot-hole film-cooling geometry. Part 2. Transonic nozzle guide vane heat transfer and loss. ASME J. Turbomachinery 124: 461-471. http://doi.org/10.1115/1.1459736

[10] Goldstein RJ, Eckert ERG, Chiang HD, Elovic E. (1985). Effect of surface roughness on film cooling performance. ASME J. Engng Gas Turbines Power 107: 111-116. http://doi.org/ 10.1115/1.3239669

[11] Schmidt DL, Bogard DG. (1996). Effects of free-stream turbulence and surface roughness on film cooling. ASME Paper. http://doi.org/10.1115/96-GT-462

[12] Schmidt DL, Sen B, Bogard DG. (1996). Effects of surface roughness on film cooling. ASME Paper. http://doi.org/10.1115/96-GT-299

[13] Yuen CHN, Martinez-Botas RF. (2003). Film cooling characteristics of a single round hole at various streamwise angles in a crossflow. Part I. Effectiveness. Int. J. Heat Mass Transfer 46: 221-235. http://doi.org/10.1016/S0017-9310(02)00274-0

[14] Yuen CHN, Martinez- RF. (2003). Film cooling characteristics of a single round hole at various streamwise angles in a crossflow. Part II. Heat transfer coefficients. Int. J. Heat Mass Transfer 46: 237-249. http://doi.org/10.1016/S0017-310(02)00273-9

[15] Yuen CHN, Martinez-Botas RF. (2005). Film cooling characteristics of rows of round holes at various streamwise angles in a crossflow. Part I. Effectiveness. Int. J. Heat Mass Transfer 48: 4995-5016. http://doi.org/10.1016/j.ijheatmasstransfer.2005.05.019

[16] Yuen CHN, Martinez-Botas RF. (2005). Film cooling characteristics of rows of round holes at various streamwise angles in a crossflow. Part II. Heat transfer coefficients. Int. J. Heat Mass Transfer 48: 5017-5035. http://doi.org/10.1016/j.ijheatmasstransfer. 2005.05.020

[17] Lucas JG, Golladay RL. (1963). An experimental investigation of gaseous film cooling of a rocket motor. NASA TN 0-1988.

[18] Kumar AL, Pisharady JC, Shine SR. (2015). Effect of injector configuration in rocket nozzle film cooling. Heat Mass Transfer. http://doi.org/10.1007/s00231-015-15907

[19] McCall JF, Branam RD. (2009). Effects of radial curvature on net heat flux reduction in a film-cooled rocket. 47th AIAA Aerospace Sciences Meeting Including the New Horizons Forum and Aerospace Exposition, AIAA, 2009-1586. http://doi.org/10.2514/6.2009-1586

[20] Nasir H, Ekkad SV, Acharya S. (2001). Effect of compound angle injection on flat surface film cooling with large streamwise injection angle. Experiment $\begin{array}{lll}\text { Thermal Fluid } & \text { Sci. 25(1/2): } 29 .\end{array}$ http://doi.org/10.1016/S0894-1777(01)00052-8

[21] Menter FR. (1994). Two-equation eddy-viscosity turbulence models for engineering applications. AIAA J. 32(8): 1598-1605. http://doi.org/10.2514/3.12149

\section{NOMENCLATURE}

$\mathrm{C}$

d

$\mathrm{d}_{\infty}$

DR

$\mathrm{M}$

$\mathrm{p}$

$\mathrm{T}$

$\mathrm{Tu}$

$\mathrm{U}$

$\mathrm{x}$

$\mathrm{y}^{+}$

\section{Greek symbols}

$\beta$

$\rho$

$\eta$

\section{Subscripts}

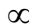

$\mathrm{c}$

$-$ dimensionless lateral curvature parameter coolant hole diameter, $\mathrm{mm}$ hot inlet wall diameter, $\mathrm{mm}$ density ratio blowing ratio hole pitch, $\mathrm{mm}$ temperature, $\mathrm{K}$ turbulence intensity velocity, $\mathrm{m} . \mathrm{s}^{-1}$ axial distance along surface, $\mathrm{mm}$ boundary layer thickness

spanwise injection angle, ${ }^{\circ}$ density, kg. $\mathrm{m}^{-3}$ film cooling effectiveness

free stream conditions Injection conditions average value 